\title{
Democracia y transparencia, una relación de complejidad
}

\section{Democracy and transparency, a relationship of complexity}

\author{
Aceptado: 15/12/2019
}

Recibido: 15/02/2019

\section{Democracia y Transparencia}

Sonia Isabel Pérez Mérida'

Mélgin Gabriel Tacám García ${ }^{2}$

Correo: doctoradoeneducacion@cunoc.edu.g†

Filiación de los autores: Universidad de San Carlos de Guatemala

https://doi.org/10.36314/revistavida.v1i1.10

\begin{abstract}
Resumen
Democracia y Transparencia, una relación de complejidad, es un reto muy grande pero interesante, fundamentar nuestra reflexión a partir de considerar que la democracia debe ser un sistema vivo, una esfera de complejidad. Un acontecimiento holográfico en donde la acción del todo influye en las partes, a la vez las acciones individuales, afectan y transforman el todo, pues compartimos una misma fórmula de origen. Mientras la democracia siga siendo considerada una proporción numérica, de participación ciudadana para la repartición, el orden profundo y subyacente del orden implicado no será posible; ni siquiera como mera ilusión tridimensional. No existe democracia fuera del ser humano, de espaldas al debate de los ciudadanos, menos sin que las realidades cotidianas de los mismos sean incluidas como ciudadanos plenos. Retomamos la necesidad del Ágora; la conversación de las plazas públicas, como pieza fundamental del sustento democrático. El sano debate de todo aquello que les compete y sobre lo cual debe realizarse los procesos dialógicos. Del Ágora hasta el Ostrakon, entendido en la actualidad como el destierro ciudadano; la muerte civil para aquel que transgreda el bien común en beneficio propio. Las diferencias y los consensos; los acuerdos y desacuerdos harán sostenible la democracia en donde el elemento central sea el ser humano plenamente incorporado y su plenitud. Democracia y transparencia como relación vivida en las esferas más profundas de la conciencia, la que complementa a los seres humanos en el afecto; el ser humano reconciliado con sus congéneres e integrado al universo del cual es parte y autor.
\end{abstract}

\section{Palabras clave}

Democracia, transparencia, ciudadanía, ágora, complejidad

\begin{abstract}
Abstrac
For the group Democracy and Transparency, a place of complexity, it is a very big but interesting challenge, to base our reflection on the basis of considering that democracy must be a living system, a sphere of complexity. A holographic space where the action of the whole influences each part, while at the same time the individual actions affect and transform the whole, because we share the same formula of origin. While democracy continues to be considered a numerical proportion, of careful participation for the distribution, the deep and underlying order of the implicate order will not be possible; not even as a mere three-dimensional illusion. There is no democracy outside the human being, with their backs to the debate of the citizens, unless their daily realities are included as full citizens. We return to the necessity of the Agora; the conversation of the public squares, as a fundamental piece of the democratic sustenance. The healthy debate of all that concerns them and on which the dialoguing processes must be carried out. From the Agora to the Ostracon, understood at present as the citizen exile: civil death for one who transgresses the common good for his own benefit. The differences and the consensus; the agreements and disagreements will make sustainable the democracy where the
\end{abstract}

1 Psicóloga, Master en Trabajo Social, Columnista, Docente de Grado y Postgrado USAC: CUSAM CUNOC.

2 Médico y Cirujano, Master en Ciencias Médicas con especialidad en Cirugía General

https://revistavidacunori.com 
central element is the fully incorporated human being and its fullness. Democracy and transparency as a space lived in the deepest spheres of consciousness, which complements human being in affection; the human being reconciled which his congeners and integrated into the universe of which he is part and author.

\section{Keywords}

Democracy, transparency, citizenship, agora, complexity

\section{Democracia}

Ausente del sentido de plenitud de la condición humana e invisibilizando las necesidades profundas de las personas; considerándolas masa y no persona, la democracia es entendida de diversas formas; desde un arreglo numérico de la imposición de las mayorías sobre las minorías, hasta el acuerdo y arreglo social en torno a las normas de convivencia y gobernanza. La clase política es considerada como operadora de las democracias, sobre todo "la política" como aquella que milita activamente en los partidos, relegando el papel de los ciudadanos a un segundo plano, convocado solamente en época electoral. Admite al militante de la política como el gran intermediador de las necesidades de los ciudadanos, frente al poder formal de las instituciones de gobierno y sus funcionarios, no sin antes reclamar para sí mismo un precio de cuota de poder por sus oficios intermediadores, que por lo general son insuficientes.

Concentrada en lo formal, en las rígidas estructuras y su funcionalidad, la definición de democracia ha dejado en el camino al ser humano y su entorno; al ser y su cotidianidad, a su entorno cultural. El enfoque tradicional pretende una condición democrática con ciudadanos en silencio, sin opinión; sin relaciones de diálogo que son el mecanismo que desencadena emociones, propicia la capacidad de sentirse parte, dueño o crítico de la cosa pública, como dice Maturana Romesín, "La Democracia es una Obra de Arte"

Despojado de toda identidad y dignidad de ser humano, la democracia apenas alcanza a definirse como un cúmulo de normativas y preceptos que de hecho no adquieren significancia en primera persona. Condena a los ciudadanos a vivir en diferido, cumpliendo siempre una agenda de poder que le es extraña. Esa estructura mecánica con la que se pretende entender la democracia, la enajena de las posibilidades del diálogo, el debate y hasta la controversia, condicionantes que pueden enriquecer el Ágora; entendida como la discusión, el diálogo en los espacios públicos del ciudadano vivo, dotado de voz y poder de decisión, que concibieron los griegos en los gérmenes democráticos.

Para el autor Humberto Maturana, es precisamente el Ágora el único mecanismo que brinda el fundamento democrático, unido a la naturaleza infantil del compartir y asumir roles sin prejuicios. Lo matrístico, venido de la cultura antigua en 
donde no existía la jerarquía patriarcal ni el arrebato; propensos a la paz, no a la guerra, comparable a la relación materno infantil, acota Maturana, como el mecanismo que nos permite superar el modelo patriarcal de las democracias.

Desde el enfoque formal, la democracia se garantiza por la presencia de diversos partidos políticos, que aceptan y asumen las reglas del juego con las cuales creen garantizada la condición democrática, por eso Norberto Bobbio hablaba de la existencia de "modelos de democracia", formalmente concebidos, a espaldas de los ciudadanos. El intermediador tramita los intereses espurios de su ambición y los intereses del poder que tiene ascendente sobre él, sin un lugar para el ser humano. Precisamente por eso Maturana resalta que las democracias concebidas en el arrebato patriarcal, en el apropiamiento de la cosa pública por unos pocos, es más lógica para la dictadura, que para la democracia; agrega: "El vivir democrático es una obra de arte, no tiene que ver con la eficiencia, no tiene que ver con la perfección, tiene que ver con el deseo de una convivencia en fraternidad". 3

Con frecuencia, el término democracia es también entendido como la norma de los sistemas políticos, a través de la participación activa en partidos políticos que constituyen la política Encargados de planificar el reparto del poder. Le asignan la interpretación de la realidad a "lo político", en donde incluyen a la academia y las instituciones nacionales e internacionales dedicadas al análisis. Con todos los problemas que de hecho afrontan los sistemas educativos en general y especialmente la educación universitaria, tal tarea es siempre insuficiente. No logran superar las amarras de los viejos paradigmas, el pensamiento mecánico y las argumentaciones reduccionistas.

En este sentido podríamos decir que los procesos educativos están diseñados para uniformar la percepción de la realidad; cultiva una visión divisiva y mecánica de la misma, que produce seres con cierta información enlatada, que no prepara la libertad de pensamiento que reta, cuestiona y busca nuevos paradigmas. Al efecto Sotolongo Codina y Carlos Delgado Díaz, en el libro La Revolución Contemporánea del Saber y la Complejidad Social, afirman que las crudas realidades contemporáneas necesitan de nuevas formas de enseñar, de paradigmas renovados en donde se supere el pensamiento fragmentado que indicaría que solo ciertas ramas del conocimiento merecen ser llamadas ciencia.

Hay más todavía, por ejemplo nos podemos referir a lo que ocurre en las distintas universidades, donde se ha abandonado el Ágora, el valor de la conversación del acuerdo y el desacuerdo, en un acto de extravío, surgido del adoptado afán por la eficiencia y tecnología. Lo político, de lo que se encarga la academia, a diferencia de la política y sus políticos, necesita retomar el valor de su capacidad de dialogar en base a nuevos paradigmas que aportan las ciencias de la com

3 Maturana, Humberto, "La Democracias es una Obra de Arte", Cooperativa Editorial Magisterio. Instituto para el Desarrollo de la Democracia Luis Carlos Galán. p.28. Colombia, 1999. 
plejidad. "La democracia es una obra de arte del conversar, del equivocarse y del ser capaz de reflexionar". ${ }^{4}$

Los sistemas educativos tienen la responsabilidad de cambiar la forma y contenidos con los cuáles se pretende acceder a un nuevo conocimiento. Es la visión de los paradigmas de segunda generación y más, lo que podrá eventualmente fundamentar los elementos pedagógicos de la democracia, necesarios para abordar los elementos del complejo entramado de la realidad. "El pensamiento moderno -con independencia de las decisiones entre partidarios de variadas doctrinas concretas- coincidió en excluir por insuficientes y vagos, los criterios de veracidad y certeza provenientes de la experiencia de la vida cotidiana". ${ }^{5}$

Esa objetividad se manifiesta en las relaciones de posibles consensos, en donde participan con más predominio aquellos ciudadanos que por estar organizados, tienen mayor incidencia en las esferas de decisión; sin embargo, estas decisiones implican: escoger y renunciar. Es un proceso de selección que genera más posibilidades de descontento que de satisfacción. La ecología de la acción de la que habla Edgar Morín en su libro La Vía.

Si por democracia se entiende la normativa del poder formal y sus instituciones, ejecutada por la acción de gobernar, con sus ideales y todos sus males, no hay forma de justificar que la construcción misma de la definición le dé más importancia a la estructura, que al sentido de realización superior, de la plenitud del ser humano, Saint Just, citado por Edgar Morín dice "Todas las artes han producido sus maravillas; solo el arte de gobernar ha producido únicamente monstruos"6 que en todo caso, encarna una combinación entre el principio de riesgo y el de precaución.

El equilibrio entre estos dos elementos -riesgo y precaución-, no es posible en ausencia del Ágora; sin diálogo ciudadano no hay democracia; será en todo caso un pacto de privilegios, que no es vivido ni reconocido por todos los ciudadanos y, que además no es parte de la vida cotidiana de personas y familias, por lo que no fecundará en las relaciones de confianza y credibilidad de la conciencia humana; no serán parte del universo en donde se funden las conciencias con el sentido de plenitud y armonía de la que hablan los saberes ancestrales.

Basados en los aportes de la Entropía, en la dinámica vibrante de la democracia -sea cual sea, será más esperable el desacuerdo que el acuerdo; sobre todo en aquellas democracias caracterizadas por las enormes distancias de la inequidad. Todas las distancias son dolorosas, pero la de los ciudadanos y sus gobernantes, suele ser trágica, De la misma forma, la grotesca distancia entre la riqueza y la pobreza condena a los ciudadanos a la precariedad. Es solamente en el arte de 4 Maturana, op.cit., 1999, pág. 31.

5 Delgado, Carlos J. "Hacia un nuevo saber. La bioética en la revolución contemporánea del saber". Universidad El Bosque. Kimpres, 2008. Pág. 47..

6 Definición de Saint Just, citado en: Morin, Edgar. "La vía para el futuro de la humanidad". Editorial Paidós. p.38. Barcelona, 2011. 
convivir y dialogar en donde las distancias se vuelven cercanías. Adquiere sentido la grandeza de las emociones que liberan un diálogo entre seres en torno a lo que les es común, pero también de lo que les hace diferentes.

El diálogo razonado podrá ayudar a algunos consensos, pero lo emocional abre insospechados niveles de unión en base a sus convicciones y también sus diferencias. "No por racional es más perfecto un mundo".

Las invisibilidades, los modelos democráticos como forma de dominación de las personas abstraídas de su cultura y de su territorio; una imposición del norte al sur, como la denomina Sotolongo Codina y Carlos Delgado, no tiene mucho sentido. Es la concepción de democracia como un instrumento de homogenización arbitraria de las sociedades para dominarlas. Los seres humanos reducidos a instrumentos, máquinas diseñadas para hacer posible modelos políticos de imposición y modelos económicos concebidos para un espacio global; para todos y para ninguno. Producen relaciones de poder en donde la mezquindad de los intereses de dominación, disfrazan de democracia la arbitrariedad del privilegio y el arrebato.

Por difícil que sea el presente, la política no puede renunciar a la utopía de convertirse en el medio por el cual se alcance la armonía relativa, el bienestar y la paz, aun cuando las posibilidades de no lograrlo, sean mucho más grandes que el triunfo en la batalla. No obstante, la democracia no es un cúmulo de buenas intenciones, es en todo caso el grito de monumentales realidades sobre las que hay que discutir, buscar los acuerdos; más allá de los centros de poder y privilegio. No hay democracia sin un lugar para lo local, en el inmenso espacio de lo global. De la misma forma las minorías, las diferencias, los pueblos originarios reclaman un lugar de dignidad en las democracias. Morin en su Obra La Vía nos dice que: la vía democratizadora es necesariamente larga y aleatoria y seguramente con final disipativo.

La democracia entendida desde el paradigma tradicional, siempre parte de la suposición de la funcionalidad de un elemento, de una pieza fundante; la bala de plata: la mayoría de las urnas, las buenas intenciones de los representantes, la transparencia de sus autoridades. Se pretenden democracias que ganen calidad en base a cantidad de forma mecánica: por cartilla o decálogo y en el peor de los casos por dominación. Cuando en un país solo una minoría de sus habitantes viven bien, no podemos hablar de un pueblo democrático. Es necesario iniciar la revolución para el cambio hacia el pensamiento complejo, en donde se involucre la sociedad para mejorar la vida de la población, poniendo como aspiración, el sentido de realización humana, en un entramado, entretejido para sentirse parte de él, como sugiere el principio de ecología profunda.

7 Maturana, op.cit., 1999, pág. 33. 
El nuevo paradigma, surgido de las ciencias de la complejidad nos dice que la realidad es un espacio vibrante y dinámico, lleno de posibilidades disipativas, en donde el observador altera lo observado. Un espacio entretejido de múltiples interacciones; sistemas vivos capaces de generar sus propios patrones de comportamiento, incluso aquellos que considerábamos menos probables o los que nos sorprenden y dan al traste con cualquier capacidad predictiva.

La democracia entendida bajo el nuevo paradigma no es una planificación inerte. Es un sistema vivo de confluencia e interacción de innumerables conciencias en los arreglos del poder, entendido este como una fuerza altamente entrópica y hasta abrasiva. Estas fuerzas signadas por el desorden, eventualmente podrán ser influenciadas por la reflexión que se aloja en el nivel básico del universo, aquel que la escritora Juventina Salgado en El Mundo Cuántico de la Conciencia, refiere como "Información Platónica" la que nos permite que nuestras acciones y elecciones sean reflexivas y no reactivas. Regreso al Ágora como principio dialogante.

Al momento de asignarle a lo político la tarea de entender la realidad, a través de la academia, la concepción tradicional de democracia, hace a un lado la profunda riqueza de los procesos dialógicos entre los ciudadanos, espacio de donde surgen los sentimientos que dan sentido de pertenencia al ciudadano. El proceso de lenguaje, dice Maturana Romesín, es el mecanismo desde el cual el ser humano puede obtener su referente válido de la realidad de la cual se siente parte y autor; lo humano se da en el lenguaje, afirma Maturana. El ciudadano en su proceso de comunicación, refiere la realidad en primera persona, en piel propia; lo que realmente vive, más allá de la arrogancia de las construcciones intelectuales, que hablan más desde sus prejuicios, que desde la realidad vivida y sentida de los ciudadanos.

Desde la complejidad y su criterio de Ecología Profunda podremos comprender que solamente cuando el ser humano se siente parte integral de los sistemas vivos y no dueño de ellos puede desempeñarse con las mismas consideraciones que guardan por sí mismos. En tanto el individualismo mezquino sea sobre-estimulado por razones de mercado y consumismo, mientras el ser humano sea ajeno y extraño a lo que ocurre en sociedad, su dinámica siempre será en contrario a la funcionalidad del sistema, precisamente porque se considera dueño de él; lo utiliza hasta destruirlo.

La democracia como planificación normativa, distante de la realidad cotidiana, ajena a los rasgos culturales, de espaldas a lo local -el reino de unos pocos con privilegios- está condenado al fracaso. Será en todo caso un cúmulo de enunciados en los que nadie cree.

La participación de cada uno de los ciudadanos, propicia cambios en nuestro entorno, económico, social, ecológico y político. La democracia históricamente 
ha marcado la evolución de la humanidad como forma de organización y toma las decisiones importantes; sin embargo la articulación ciudadana sigue siendo el gran pendiente. En tal sentido, Maturana Romesín decía: "La democracia no está en la rotación, en la elección de representantes. Los sistemas electorales son artificios para la apropiación de las responsabilidades. La democracia está en una convivencia en la cual todos los ciudadanos tienen acceso a la cosa pública y la cosa pública son los temas que interesan a todos los ciudadanos como coparticipantes de una convivencia en una comunidad".

La filosofía perenne ha retado las respuestas que por siglos se le dieron a las principales preguntas de la filosofía y sin duda la resistencia al cambio es grande. Años y siglos dando por ciertas las afirmaciones científicas reduccionistas, han influenciado la forma en que nos explicamos, entre muchas otras cosas la democracia. El nuevo paradigma dice que conciencia-observador pueden crear o modificar la realidad, por lo tanto la democracia solo puede tener nuevas y renovadas calidades en función de sus ciudadanos, no de su normativa como letra muerta. Al interactuar con el universo y la fuerza o energía que se libera de nuestras interacciones con el entorno, se producen los motivos para dialogar; el contenido del Ágora. Al observar o estudiar la realidad la modificamos "conocimiento íntimo de la realidad, más allá de los símbolos de la ciencia".?

Cómo puede pretenderse cualquier aproximación democrática con individuos sometidos al silencio, a discursos que robotizan sus percepciones; diálogos a partir del despojo de su más elemental sentido de dignidad y pertenencia; impedidos de la conversación que produce consenso o bien, su derecho al disenso.

El reconocimiento de la coexistencia del orden, desorden en el mar de lo azaroso, es un pensamiento que permite asomarse a la complejidad. La construcción de la democracia necesita de las fuerzas vivas de la ciudadanía; de las contradicciones previas a los acuerdos, del derecho a dialogar en primera persona y sin falsas intermediaciones, como sucede en las democracias representativas. Ejercer el Ágora en un mundo de ideas, lenguaje y conciencia. Fundamentados en un paradigma que contemple distinción y conjunción; que permita distinguir sin desarticular. Una propuesta para civilizar la democracia.

Para crear nuestro mundo tenemos que interactuar con este para poder crear la realidad que esperamos. Al estar en un determinado sitio reflexionamos sobre lo que nos rodea, nos damos cuenta que puede ser solo una ilusión creada en nuestra mente. La democracia plena emerge en el resultado de las interacciones y al mismo tiempo se recrea a sí misma en la vida real de cada persona, en aquellas experiencias que les haga sentir que su origen, su color de piel, sus rasgos culturales crean respeto y no segregación. Ni siquiera las condiciones materiales de vida son más poderosas que el sentido de dignidad del ser humano, la plenitud

8 Maturana, op.cit., 1999, pág. 26.

9 Definición Eddington, citado en: Wilber, Ken. "Cuestiones cuánticas. Escritos místicos de los físicos más famosos del mundo". Editorial Kairos. 6ª Edición. p.172. Barcelona, 1987. 
de sentirse parte de lo que le es propio: su identidad. Por eso Maturana dice que la democracia no es cuestión de poder ni de condiciones materiales, es plenitud.

La tradición occidental siempre ha concebido la disyunción espiritual y científica, no obstante como seres humanos sobrevivimos a las pautas y ritmos de la complementariedad y en atención a nuestras particulares características. Precisamente cuando nos sumergimos en mundos y conocimientos desconocidos, nos hallamos en cierto sentido en aparentes complicaciones al querer entenderlos y explicarlos; sin embargo los arreglos de convivencia, dentro de los cuales se encuentra la democracia, solo serán racionalizados después de vivirlos, no al revés.

Bajo el enfoque de la complejidad, democracia es un sistema vivo, con elementos interconectados cuyos vínculos crean dinámicas e información adicional, no siempre visible para el observador. Los componentes que interactúan en democracia: la política y sus políticos, las correlaciones de poder, los actores sociales, ciudadanía; necesidades y satisfactores, al relacionarse entre sí, poseen más información que cada uno de esos elementos en lo individual. De esa interacción emergen propiedades y rasgos nuevos, insospechados que no pueden ser explicados a partir de cada individualidad. Precisamente por eso la insistencia de los conceptos de individualismo, no han podido abonar a la democracia; sobre todo en materia de calidad de vida de las personas.

Entender la democracia bajo la complejidad, implica diferenciarla del concepto tradicional de complicado. Lo complicado está formado por varias partes, pero la ausencia de interrelaciones significativas hace que las partes no añadan información ni dinámica adicional al sistema; es una suma mecánica. Las democracias fundadas y explicadas bajo el paradigma tradicional son complicadas, no complejas, por eso están condenadas a dar vueltas sobre sí mismas, con resultados cada vez peores que su precedente. Son democracias centradas en las normas pétreas, no en la viveza de la complejidad del sentido humano y la ética del bien colectivo superior.

Para Morin la democracia se entiende como un bucle entre individuo y sociedad: "Individuo y Sociedad existen mutuamente. La democracia permite la relación rica y compleja individuo-sociedad, donde los individuos y la sociedad pueden entre sí ayudarse, desarrollarse, regularse y controlarse". ${ }^{10}$

Más que un régimen político, la regeneración continua de un bucle complejo y retroactivo, dijo.

La concepción de la democracia como sistema vivo implica niveles elevados de reflexión y propósito, que aporta formas renovadas de interacción y con ello la posibilidad de la emergencia de nuevas y mejores propiedades, como aporte de los elementos o componentes interactuantes. Sotolongo Codina y Delgado Díaz 10 Morin, Edgar. "Los siete saberes necesarios para la educación del futuro". Organización de las Naciones Unidas para la Educación, la Ciencia y la Cultura UNESCO. UNESCO, Francia 1999. Pág. 55. 
piensan que es necesario tener una visión crítica del cambio social a partir de una concepción no lineal de las sociedades y la forma en que se pretende explicar el modelo llamado Democracia.

La democracia tendrá un sentido sostenible, cuando sea producto del diálogo de sus ciudadanos; no imposiciones prediseñadas para dominar; para lograr un mundo embotadamente uniforme sin identidad ni referentes culturales que les fortalezcan. La nueva forma de dominación.

En Guatemala se puede identificar en la llamada Primavera Democrática (19441954), específicamente en el período del Presidente Jacobo Árbenz Guzmán, el ejercicio democrático más consistente hasta ahora, con un norte claro de inclusión de los sectores vivos de este país como partícipes activos, dialogantes en los asuntos públicos que les eran propios y parte de sus hondas preocupaciones y realidades de vida. El pueblo de Guatemala fue violentamente despojado de su democracia, mediante intervención de Estados Unidos, usando falaces argumentos que animaban la guerra fría. Los guatemaltecos fuimos condenados a ser "otros", impedidos de construir el sentido profundo de "nosotros"

En ocasión de la toma de posesión de Jacobo Árbenz Guzmán (15 de Marzo1954, Gaceta Oficial de Guatemala) su discurso reflejaba la estatura cualitativa y humana de los pilares de aquella breve pero imborrable democracia: "Y cuando hablamos de nuestros problemas sociales no debemos apartar la mirada de los grupos indígenas de Guatemala ni de las necesidades propias de la juventud y la mujer. Dentro de la consideración que nos merece elevar el estándar de la vida del pueblo en general, debemos considerar con cuidados especiales a nuestras mejores reservas, a la gran población indígena, y a los jóvenes y a las mujeres en general, como los tesoros más preciados de nuestra riqueza humana.... Conglomerados de hombres y mujeres bien alimentados, sanos, cultos y más felices". ${ }^{11}$

Con claridad meridiana en el diálogo, la inclusión y las emociones como elemento central de la democracia, Árbenz Guzmán dejó en Guatemala y sus guatemaltecos el período más luminoso en materia de democracia y la herida más honda por su arrebatamiento. Precedido por Juan José Arévalo Bermejo, de inspiración humanista, Jacobo Árbenz Guzmán, no ignoraba los retos de esa construcción ciudadana, muy adelantada para su época y los estándares de la región. Tal vez por eso en la parte final de su discurso decía: "Por último me permito exhortar de nuevo a los sectores populares, a los distintos grupos políticos que mantienen vivo el espíritu de la democracia y de la Revolución de Octubre, a que aúnen sus esfuerzos, a que se conviertan en un haz apretado de voluntades dispuestas a resistir los embates del porvenir, a sacrificar posiciones personalistas para poder librar

11 Wikisources. "Discurso de toma de posesión del Presidente Jacobo Árbenz". https://es.wikisource.org/wiki/ Discurso_de_toma_de_posesi\%C3\%B3n_del_Presidente_Jacobo_\%C3\%81 rbenz. Consulta realizada el 12 de abril de 2018. 
al régimen libre de Guatemala de todas las acechanzas y para cumplir con éxito y con honor el programa que nos ha encomendado el pueblo guatemalteco". ${ }^{2}$

Es en nuestro diario vivir, en la convivencia dialogante y armónica por un bien superior y en un plano integrado de la conciencia que parten según Ken Wilber de las tres esferas del conocimiento; Empírico, racional y contemplativo en donde podemos ascender a la armonización de los individuos con el universo, con el entorno del cuál es parte y no espectador.

Habrá democracia solamente a partir de la plenitud, no de la norma arbitraria; construida en constante participación ciudadana en beneficio de la comunidad, no de un proyecto global de robotización. Jacobo Árbenz Guzmán en aquel memorable discurso decía: ". Los ciudadanos mantengan su derecho de pensar y creer como quieran, a organizarse y a dedicarse a las actividades lícitas que quieran". ${ }^{13}$

Las sociedades dedicadas a convertir al ciudadano en un número, empeñadas en una ciencia arrogante, segmentada y unilateral, que desprecia el valor del Ágora y, en esa tónica estrecha, ha querido refrendar democracias de diseño uniformador, sin ciudadanos admitidos como seres humanos; sin derecho a sus rasgos culturales, llevando su cotidianidad como un elemento callado y clandestino. Este criterio pobre de mutilaciones mecanicistas, no puede aspirar a ser la "Primavera Democrática" de la que fuimos despojados. Ausentes en el diálogo y suplantados por la supremacía de la tecnología por encima del ser humano al punto que Stephen Hawking, en su libro El Universo En Una Cáscara de Nuez, advierte que la especie humana tiene que aumentar su complejidad si queremos que los seres biológicos se mantengan delante de los "seres" electrónicos.

Las sociedades deberán dar paso a la revolución del pensamiento, a los nuevos paradigmas para democracias de los humanos, entretejidos y dialogantes para no sucumbir a las democracias de los votos y el papel. El Ágora que da voz, participación y vida a los ciudadanos, como el ejercicio humano que lo coloca en la ruta de un entretejido diálogo propio y genuino, que lo haga un ser integrado con su universo; pleno y feliz.

\section{Transparencia}

A falta de referente humano, de sentido de vida real y, en una época en donde las mecánicas y utilitaristas democracias se tambalean en sus propios argumentos, la transparencia es el concepto de moda; la joya de la corona. Definida, desde la concepción tradicional como la rendición de cuentas de los funcionarios

12 Wikisources. Op.cit.

13 Wikisources. "Discurso de toma de posesión del Presidente Jacobo Árbenz". https://es.wikisource.org/wiki/ Discurso_de_toma_de_posesi\%C3\%B3n_del_Presidente_Jacobo_\%C3\%81 rbenz. Consulta realizada el 12 de abril de 2018. 
de gobierno, individuos y actores en relación con las acciones de las instituciones de los poderes del Estado. Es concebida como la observancia de los marcos legales que rigen la función pública: habilitaciones y prohibiciones; en el sentido más positivista de la palabra.

Es el criterio de individualidad el que anima la definición de transparencia, concebido para no ser discutido ni refrendado; solo acatado. Herencia de la inspiración patriarcal y jerárquica de nuestras democracias, que parten del principio de un mundo unilateral, en donde creen suficiente que algo que parece deseable, sea decretado, desde la piedra filosofal del poder para que suceda.

De inspiración unilateral, como herramienta de uniformidad global, la transparencia es impuesta a las naciones como la tarea en boga. No parte del diálogo ciudadano, del Ágora, a pesar de ser evidente el cansancio ciudadano por el arrebatamiento de la cosa pública y la corruptela descarada. Es un intento de homogenización a través de un elemento aislado y dicotómico. Carlos Delgado Díaz refiere que la homogenización es un mecanismo que conduce al empobrecimiento de la diversidad espiritual humana, propicia la exclusión y destrucción del otro.

Desde los inicios de la democracia en la antigua Grecia, la práctica del Ostracismo (Ostrakon) era el mecanismo por el cual, eran desterrados, los gobernantes o personas con roles relevantes que de alguna manera atentaban contra la cosa pública. La democracia iba desde el Ágora hasta el Ostrakon, como mecanismo de regulación de la democracia. El rasgo fundamental, radicaba en que empezaba con el diálogo en la plaza pública hasta el castigo del destierro por votación, escrita en pequeños trozos irregulares de arcilla. Diálogo sobre lo que interesaba a los ciudadanos y diálogo para el destierro.

Desde lo formal normativo, la transparencia es un imperativo de ley, esencialmente punitivo, pues la inobservancia de los marcos legales en esa materia conlleva procesos judiciales. En algunos países llega hasta la muerte civil, que es la inhabilitación para participar de por vida en la función pública. La parte punitiva es ejercida más desde la letra muerta de la ley, que desde el diálogo. La acción del observador como externo y con ascendente sobre lo observado.

Humberto Maturana habla del observador en la experiencia de observar como la relación generativa entre la explicación y lo explicado, la realidad pertenece al explicar del vivir, no como un agente externo que con su pensamiento y su conciencia se erige como el gran calificador externo de la realidad. Concibe al observador como parte dinámica del sistema vivo.

La ética de la transparencia tiene que ver con nuestras emociones no con nuestra racionalidad. Es por eso que cuando los actos de corrupción son perseguidos con sentido externo al sistema, cada vez más ciudadanos sienten que el círculo 
se cierra más cerca de él o de su entorno, por razones arbitrarias, muy lejanas a lo que constituyen sus preocupaciones cotidianas.

Vivimos en nuestras interrelaciones los intereses éticos, ocurren, no controlamos su ocurrencia. Por esto la llamada "información platónica" de Penrose que cita Juventina Salgado, aquella que posibilita el plano de las elecciones y decisiones que tomamos y, que si logramos hacerlas reflexivas y sensatas nos eleva a planos de un bien superior del universo de la conciencia y de ella misma. Solo entonces pasan a formar parte de aquello que nos preocupa y nos importa porque es parte de nosotros mismos. Importará a los ciudadanos en tanto sea un factor dialógico, no enteramente impositivo por razones de dominación global.

Partiendo del supuesto de que lo que observamos en la "realidad" no es más que una ilusión de la conciencia; el universo explicado del que nos hablan las ciencias de la complejidad. Admitiendo además la existencia de una realidad sutil y trascendente que podemos conocer solo bajo el dominio del lenguaje, no parece posible un modelo democrático de espaldas al Ágora y por tanto lo punitivo de la concepción global de transparencia, como elemento aislado, no llegará al Ostrakón como un mecanismo social válido. Será en todo caso un mecanismo para dirimir el poder, que no despertará la conciencia profunda que requiere la democracia entendida como sistema vivo.

Sin la trascendencia de la complejidad, siendo que nuestro mundo tal vez sea solamente una proyección de nuestra conciencia; una realidad que se encuentra más allá del tiempo y del espacio; cabría preguntarse qué condiciones o eventos y bajo qué dinámica se desencadena ese océano vibrante y oscilante de la conciencia del que nos habla el nuevo paradigma. Alejado de una sustentación profunda y entretejida, democracia y transparencia serán solamente una cadena aislada de elementos, condenados a no tener resonancia ni cercanía con el criterio de plenitud ciudadana. Forasteras en los espacios en donde se vive la cotidianidad, la cultura y la emoción humana.

Los fenómenos del universo se materializan por la acción de la conciencia, solo la praxis del observador, la interacción del observador de lo observado puede dar sentido a la objetividad con paréntesis, como le llama Maturana, aquella surgida de la práctica vívida de dialogar. La praxis es validada por sí misma, por lo que considera superfluas las explicaciones. Toda explicación es secundaria al hecho de encontrarnos haciendo lo que hacemos, la experiencia de hacerlo. Partiendo del aporte de Maturana, si el que se erige como calificador externo y jerárquico de la transparencia, no la refrenda con su práctica, no podrá crear instancias válidas de credibilidad y coherencia. Será en todo caso, una acción nula e intrascendente.

La visión normativo-punitiva, puede ser redactada, formulada y promulgada técnicamente impecable; sin embargo mientras siga siendo un elemento aislado, 
fuera del sistema vivo de entre los humanos, seguirá siendo letra muerta. Lo que Ken Wilber ubica en el dualismo cuaternario: la lucha del individuo con sus pulsiones más oscuras e inconfesables. Entendiendo que en sociedades de seres solitarios, en donde el lenguaje consensuado del que habla Maturana, tiende a la extinción; sin dudarlo, ganará siempre la sombra.

Transparencia es definida también como un mecanismo que desde lo legal intenta regular los excesos del poder, sobre todo en materia de enriquecimiento ilícito; el uso del erario público como botín de poder, en donde participan no solo funcionarios públicos. Elites empresariales, de la más conservadora composición que han usado el dinero público para incrementar fortunas coloniales de forma exponencial. El apetito de enriquecimiento voraz ha estado aparejado al poder y presente en democracias dicotómicas "Los hombres son pervertidos no tanto por la riqueza como por el afán de riqueza"14 Louis de Bonald.

La ecología profunda incorpora al individuo como parte integrante, activa y dinámica del sistema vivo; por tanto su existencia está ligada a la del sistema. Cuando la transparencia es concebida como un superpuesto fuera del sistema, en donde la cosa pública ya le ha sido arrebatada al ciudadano - como afirma Maturana-, la propensión será hacer todo lo que dañe el sistema en beneficio de un individuo y su ambición o de un grupo con poderes, casi monárquicos. Organismo versus medio ambiente, como el Dualismo Primario del espectro de la conciencia del que hablaba Wilber.

Visiones más ciudadanas definen transparencia como el elemento más utópico del modelo de Estado- mercado, parte del marketing con el que se pretende justificar un componente prácticamente imposible de alcanzar, bajo la óptica del individualismo voraz del consumismo y su simbología de suntuosidad. La supremacía de los intereses financieros internacionales, haría prácticamente imposible la probidad de los funcionarios públicos, en virtud del enorme poder corruptor de los flujos financieros espurios que circulan con impunidad a nivel global; francamente reñido con cualquier consideración ética.

Se observa un divorcio, una incisión entre lo que la parte normativa indica en materia de probidad y el contenido que los ciudadanos internalizan en las más profundas esferas del plano de la conciencia. Su propensión al individualismo sobrecogido por la ambición, entendido como el Dualismo Secundario de Ken Wilber, solo producirá la lucha de unos contra otros, en tanto individualidades; sin espacios comunes que les motive emociones profundas de pertenencia e interconexión.

Los preceptos formales de la transparencia, basados en el deber ser, chocan de frente contra la enseñanza simbólica de triunfo. La tenencia desenfrenada por bienes de consumo le ha ganado la batalla a lo normativo. La enseñanza universi-

14 http://www.proverbia.net/cita.asp?id=453059636. Consulta realizada el 5 de abril de 2018. 
taria se ha quedado en la esfera de lo correcto y adecuado, pero sin mayor oportunidad para el disenso; sobre todo en los principios fragmentarios con los cuales se intentan el estudio de las ciencias y su afán por encontrar respuestas únicas a realidades complicadas. En buena medida las universidades le han dado la espalda al Ágora, como figura válida, esencial y entrañable de la vida ciudadana. Con ello el peligro de dedicarse al estudio fragmentado y mutilado de la realidad.

Por mucho tiempo se pensó que la transparencia sería un elemento garantizado, después de superar la etapa de las dictaduras en Latinoamérica, pero no fue así. Los niveles de corrupción creciente ha sido el proceso que corroe las incipientes democracias y le resta cualquier posibilidad de concreción a la política pública, por bien diseñada que esté desde el papel. La transparencia ocurre dentro de procesos en donde se dirime el poder y por tanto está sujeta a sus influjos.

La transparencia punitiva de papel, un Ostrakón sin Ágora como precedente, es incompleto y de corta duración. Solamente dura, mientras el poder de la ambición se reorganiza para posicionarse de nuevo en el botín de la cosa pública. La sombra de las conciencias (Wilber), latente pero con fuerza, vuelve irremediablemente. A este respecto la frase de Morín sentencia: "No olvides que la realidad es cambiante, no olvides que lo nuevo puede surgir, y de todos modos, va a surgir". ${ }^{15}$

Las tendencias democráticas que procuran que las acciones de poder; sus individuos y sus actores den cuentas públicamente; desde una lógica de rendición de cuentas, piensan que entre más públicas sean las acciones de los funcionarios y los empresarios, mayor será el poder disuasivo del repudio social e internacional por los corruptos, Bajo este enfoque, lo punitivo de las leyes locales, pasa a un plano menos preponderante porque es mucho más temible el desprecio de una sociedad global. "Transparencia y verdad no son idénticas. El imperativo de la transparencia hace sospechoso todo lo que no se somete a la visibilidad, En eso consiste su violencia"16 Byung-Chul Han, Julen.

La apuesta para crear las condiciones del ejercicio del poder, socialmente vigilado a nivel planetario, adolece de una falencia de origen: al nacer las democracias de espaldas al diálogo y el sentido de plenitud de sus ciudadanos, el Ostrakón es de corta validez. Nace inválido de Ágora y por tanto débil y titubeante en el Ostrakón.

El componente punitivo de la transparencia, a través de los marcos legales no escapa a los privilegios de las élites; sobre todo en Latinoamérica. En tal sentido Pablo Neruda dijo "El fuero para el gran ladrón, la cárcel para el que roba un

15 http://www.ugr.es/ pgomez/docencia/tc/documentos/Morin_introduccion-pensamientocomplejo.htm. Consultado el 2 de abril de 2018.

$16 \mathrm{http} / / /$ blog.consultorartesano.com/2015/02/12-citas-de-la-sociedad-de-la-transparencia-de-byungchul-han.html. Consultado el 28 de marzo de 2018. 
pan" $1 .{ }^{17}$ Es que el poder formal de las instituciones del Estado y el poder real de los privilegios, tradicionalmente ha sido copado por los rostros y apellidos del privilegio, casi colonial. No hay independencia real de la acción de la justicia, amanuense eterna del privilegio.

El privilegio no se da en el Ágora pues los espacios dialogantes generan mecanismos de control ciudadano, válidos y refrendados dialógicamente. Fuera del Ágora es posible el arrebatamiento violento, arbitrario y patriarcal; es el despojo de lo que le es propio a sus ciudadanos. No es un arrebato solo de recursos y bienes materiales, es la usurpación del sentido humano, cultural e identitario de las sociedades. El hurto de su felicidad y la imposición de la norma. Una especie de homicidio cultural para dominar, similar al pensamiento de Maquiavelo que afirmaba que quien posee el poder ha de ejercerlo con toda la fuerza y rápidamente, para que a los dominados no les quede más aliento que para la resignación.

Las democracias del voto y el papel, las falsas democracias son el reino de los privilegios arbitrarios y territorio para el castigo selectivo. La parte punitiva por falta de transparencia no es el consenso del Ostrakón; es otra forma de poder que segrega para ejercicios de "limpieza" política.

El paradigma de la complejidad sabe que a través de un componente no puede definirse el todo; son sus entrelazamientos y los patrones que se generan lo que finalmente define el sistema, el todo. En base al enfoque de la complejidad sabemos que la transparencia como elemento aislado no puede definir la calidad de una democracia, en todo caso será la forma que se entrelaza con los otros elementos y la dinámica que desarrolla en la misma, signada siempre por el orden y desorden; equilibrio y desequilibrio en movimiento complementario y a la vez. Que la emergencia de lo espontáneo, el componente de lo local, lo humano y lo universal del holograma es algo muy superior. Es más profundo y complejo de lo que están dispuestos a admitir desde el enfoque tradicional.

\section{Reflexiones finales}

La democracia entendida en sus partes, no en el "todo" externa y ajena, resultado automático de la observancia mecánica de los marcos legales, considerada una objetivación, no tiene la posibilidad de ser emergencia de interacciones consensuadas que ponga a los ciudadanos en niveles de conciencia y principios éticos. Entendida como categoría aislada, siempre estará pensando con el pragmatismo mecánico de la individualidad.

La democracia que tenemos nos refleja pero no nos exime del reto de transitar por ella y en busca de ella, en el mismo acto.

17 http://sabidurias.com/cita/es/5776/pablo-neruda/el-fuero-para-el-gran-ladrn-la-crcel-para-el-que- roba-unpan. Consultado el 28 de marzo de 2018. 
Si nos atenemos a la tesis de "si cambian las partes cambia todo" y viceversa, podríamos deducir que lo que cada ciudadano haga en lo individual, se lo hace a sí mismo. La aceptación o el rechazo de la consecuencia de lo que hacemos, constituye nuestra libertad. Hemos perdido la sabiduría como un aspecto cotidiano del vivir en base a mapeos, por lo general arbitrarios, que serían equivalentes al orden explicado. Al intentar comprender la transparencia, lo hacemos con mapas mentales que nos desorientan porque la creemos ajena y distante de nosotros mismos. Creemos que un solo elemento puede definir al sistema, al todo y nos estamos equivocando de nuevo.

Los marcos legales que regulan nuestra vida en democracia, elevados a calidad de Tótem de la que habló Freud y Jung; irradiante y amenazante por sí mismo, entendido como lo objetivo externo, no convertirá onda en partícula; no habrá quantum.

La Democracia Transparente, en su mejor versión, ha sido entendida como un listado de buenas intenciones; sin embargo no llegan a ser experiencia vivida. No se eleva a planos de la conciencia, por tanto no forma parte del universo. No activará el río de posibilidades que están contenidas en los espacios profundos del holograma.

Las democracias deben ser refundadas con criterio hologramático, por difícil que sea la tarea; sin caer en la trampa del simplismo mecánico de considerar que la transparencia es a la democracia, como la tapa al pomo. Así como en el universo y la naturaleza, todo se encuentra de alguna manera interconectado, cooperando y siendo solidario para permitir el desarrollo y la vida del sistema, cada ciudadano en convivencia y armonía con sus semejantes, conformará el tejido social que permita el desenvolvimiento de las ciudades y de los Estados; de la democracia.

La consolidación de la democracia no será posible sin la incorporación del Ágora, dialogante, inclusivo y público, que convoca a todos sus ciudadanos con categoría humana y fraterna; aun en el disenso. Democracias surgidas a partir del diálogo que religa, que orienta al sentido de plenitud, profundamente humana y fulgurante, como un día surgiera de la Primavera Democrática de Jacobo Árbenz Guzmán. De ese profundo sentido compartido de ser "nosotros". Del Ágora al Ostrakón, con sentido de diálogo consensuado, aquel que convoca a los niveles más profundos de la conciencia. Individuo fundido con el universo no contra él. 


\section{Fuentes de Consulta \\ Publicaciones}

Capra Fritjof, "La Trama De La Vida" Editorial Anagrama. Barcelona 1998.

Delgado, Carlos J., "Hacia un nuevo saber. La bioética en la revolución contemporánea del saber".

Universidad El Bosque, Kimpres, 2008.

Maturana, Humberto, "La Democracias es una Obra de Arte" Cooperativa Editorial Magisterio. Instituto para el Desarrollo de la Democracia Luis Carlos Galán. Colombia, 1999.

Morin, Edgar, "La vía para el futuro de la humanidad". Editorial Paidós. Barcelona, 2011.

Morin, Edgar, "Los siete saberes necesarios para la educación del futuro". Organización de las Naciones Unidas para la Educación, la Ciencia y la Cultura UNESCO. UNESCO, Francia 1999.

Salgado Román Juventina, "El Mundo Cuántico De la Conciencia" Ediciones Eón, Universidad Autónoma de Guerrero. 2015.

Salazar Carrión Luis, "Para Pensar en Democracia" Fontamara. 1998.

Wilber, Ken, "Cuestiones cuánticas. Escritos místicos de los físicos más famosos del mundo".

Editorial Kairos. 6ª Edición. Barcelona, 1987.

\section{Fuentes digitales}

Wikisources."Discurso de toma de posesión del Presidente Jacobo Árbenz".

https://es.wikisource.org/wiki/Discurso_de_toma_de_posesi\%C3\%B3n_del_Presidente_Jacobo_\%C3\%81rbenz. Consulta realizada el 12 de abril de 2018.

http://www.proverbia.net/cita.asp?id=453059636. Consulta realizada el 5 de abril de 2018. http://www.ugr.es/ pgomez/docencia/tc/documentos/Morin_introduccion-pensamiento-complejo.htm. Consultado el 2 de abril de 2018.

http://blog.consultorartesano.com/2015/02/12-citas-de-la-sociedad-de-la-transparencia-de-byung- chul-han.html. Consultado el 28 de marzo de 2018. 
http://sabidurias.com/cita/es/5776/pablo-neruda/el-fuero-para-el-gran-ladrn-lacrcel-para-el-que- roba-un-pan. Consultado el 28 de marzo de 2018.

\section{Biografía de los autores}

Estudiantes del Doctorado en Investigación en Educación en el Centro Universitario de Occidente -CUNOC de la Universidad de San Carlos de Guatemala.

Los textos publicados son responsabilidad de los autores.

Copyright $\odot$ 2019. Los derechos son de los autores. Sonia Isabel Pérez Mérida, Mélgin Gabriel Tacám García

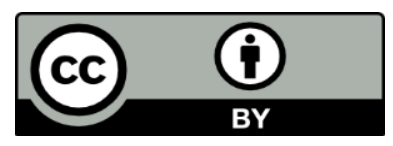

Los textos están protegidos por una licencia Creative Commons 4.0 Internacional Usted es libre de compartir, copiar y redistribuir el material en cualquier medio 0 formato y adaptar el documento, remezclar, transformar y crear a partir del material, siempre que cumpla con la condición de atribución, debe reconocer el crédito de la obra de manera adecuada.

\section{El manuscrito es de acceso abierto}

